\title{
Behavioral Teratogenicity Induced by Nonforced Maternal Nicotine Consumption
}

\author{
Rodrigo Paz ${ }^{1,2,3}$, Brigg Barsness ${ }^{4}$, Trevor Martenson ${ }^{4}$, Daniel Tanner' and Andrea M Allan*,1 \\ 'Department of Neurosciences, University of New Mexico, Albuquerque, NM, USA; ${ }^{2}$ Departamento de Psiquiatría y Neurociencias, Universidad \\ Diego Portales, Portales, Chile; ${ }^{3}$ Instituto Psiquiátrico Dr José Horwitz Barak, Santiago de Chile, Chile; ${ }^{4}$ School of Medicine, University of New \\ Mexico, Albuquerque, NM, USA
}

\begin{abstract}
Prenatal nicotine exposure (PNE) has been associated with increased prevalence of attention deficit hyperactivity disorder (ADHD), major depressive disorder (MDD) and substance abuse in exposed children and adolescents. Whether these syndromes are caused by nicotine exposure, or genetic and psychosocial adversities associated with maternal smoking is not completely clear. Animal models suggest a direct impact of PNE. However, the fact that nicotine is forcefully administrated in these paradigms raises some questions about the specificity of these findings. Pregnant C57BI/6J mice were allowed to choose drinking saccharin/nicotine solutions or pure water. Controls could choose saccharin solutions or pure water. Offspring were tested in spontaneous locomotion, fear-associated learning (trace conditioning), addictive (conditioned place preference), and depression-like (learned helplessness) behaviors. There was no significant difference in weight or pup number between the prenatal treatment groups. A significant effect of PNE was observed on spontaneous locomotion, preference for a cocaine-associated place, and latency to escape in the learned helplessness paradigm. Surprisingly, PNE mice exhibited an increased learning of trace-conditioned fear-associated cues. The hyperlocomotive behavior reported in animal models of PNE is not likely an artifact of forceful nicotine administration. The increased prevalence of ADHD, MDD and substance abuse observed in PNE children and adolescents is probably caused by direct behavioral teratogenic effects of PNE. The role of PNE as a risk factor of syndromes associated to increased learning of fear-associated cues such as post-traumatic stress disorder (PTSD) warrants further evaluation.
\end{abstract}

Neuropsychopharmacology (2007) 32, 693-699. doi: I 0.I038/sj.npp. I 30 I066; published online 22 March 2006

Keywords: prenatal; nicotine; ADHD; substance abuse; PTSD; depression

\section{INTRODUCTION}

It is estimated that $11 \%$ of US mothers smoke during their pregnancy (Martin et al, 2005). Clinical and epidemiological studies indicate that children and adolescents exposed to nicotine in uterus have an increased risk of attention deficit hyperactivity disorder (ADHD), major depressive disorder (MDD) and substance abuse (Milberger et al, 1996; Fergusson et al, 1998; Weissman et al, 1999; Mick et al, 2002; Thapar et al, 2003; Maughan et al, 2004; Linnet et al, 2005). However, because of the high comorbidity between nicotine addiction and other neuropsychiatric conditions, it has been hard to establish a direct causal link between maternal nicotine consumption and the behavioral abnormalities observed in exposed children and adolescents

\footnotetext{
*Correspondence: Dr AM Allan, Department of Neurosciences, University of New Mexico, Albuquerque, NM 87131-0001, USA, Tel: + | 50527288 I I, Fax: + | 5052728082 ,

E-mail: aallan@salud.unm.edu

Received 27 December 2005; revised 3 February 2006; accepted 9 February 2006

Online publication: 16 February 2006 at http://www.acnp.org/citations/ Npp021606050769/default.pdf
}

(Maughan et al, 2004). Offspring of rats forcefully exposed to nicotine during pregnancy (eg, continuous mini-pump infusion, injections or vapor inhalation) exhibit increased spontaneous locomotion (reviewed by Ernst et al, 2001). These findings suggest that the high prevalence of ADHD reported in PNE children could be caused by behavioral teratogenic effects of intrauterus brain exposure to nicotine (Slotkin, 1998; Slotkin, 2004). However, some additional issues need to be addressed to better support this hypothesis. First, in certain methods using the forceful administration of nicotine, the stress-response systems may be activated in rat dams and this could induce behavioral abnormalities in offspring because of the well-known impact of maternal stress on brain development and behavior (Kofman, 2002). While forced administration paradigms do control for the impact of stress by use of control groups, an interaction between stress and nicotine cannot be accounted for in these designs. Second, retarded intrauterine growth and diminished birth-weight has been reported in PNE children (Olsen, 1992; Eskenazi et al, 1995) and rat-pups (Ernst et al, 2001) raising the possibility that the behavioral abnormalities associated to PNE could be mediated by impaired brain nutrition; independent of 
pathologic stimulation of acetyl-choline nicotinic receptors in the developing brain. In addition, other behavioral outcomes associated to PNE in humans, such as substance abuse and depression-like behaviors have not been explored in available animal models of PNE (Fergusson et al, 1998). To address these issues, an experimental paradigm using voluntary nicotine consumption was developed. The impact of PNE on locomotion, learning of contextual cues associated to cocaine exposure and depression-like behavior (latency to escape in a learned helplessness paradigm) was evaluated. Learning disabilities have been also described in clinical studies of children (Fried et al, 2003; Cornelius et al, 2001), as well as rats exposed to nicotine in uterus (reviewed by Ernst et al, 2001). To examine the impact of PNE on learning capabilities, nicotine and control mice were also tested in trace fear conditioning, a fear-learning task dependent on the functional integrity of the hippocampal formation and prefrontal cortex (Han et al, 2003; Fendt et al, 2005).

\section{METHODS}

\section{Animals}

All behavior tests were conducted on adult (60-100 days of age) offspring of C57BI/6J dams prenatally exposed to saccharin solution plus $0.05 \mathrm{mg} / \mathrm{ml}$ nicotine or saccharin sweetened water were housed in a temperature controlled vivarium with $12 \mathrm{~h}$ light/dark cycle. Mice were provided standard laboratory mouse chow and tap water ad libitum. Experimentally naive mice were used in all the tests. All animal procedures were approved by the Institutional Animal Care and Use Committee.

\section{Prenatal Nicotine Exposure}

Prenatal nicotine exposure was performed using a modification of the sucrose-fading method (Slawecki et al, 1997). C57BI/6J female mice were offered $22 \mathrm{~h}$ free access to either; $0.066 \%$ saccharin $/ 99.934 \%$ water solution or pure water for 2 weeks. Next, nicotine was introduced to the saccharin tube for the experimental groups, while the control group continued to have access to saccharin alone. Mice received $0.05 \mathrm{mg} / \mathrm{ml}$ nicotine hydrogen tartrate, and nicotine concentration was increased every 3 days from 0 to $0.01,0.025$ and finally to $0.05 \mathrm{mg} / \mathrm{ml}$, to remain constant at this level for the rest of pregnancy. Consumption of water, saccharin/ water plus nicotine, and saccharin/water solutions were measured during all pregnancy. After 2 weeks of drinking, females were placed on breeder chow and a male mouse was introduced into the female's cage. Once the female was determined to be pregnant, the male was removed and nesting material was placed in the cage. Within 1 day of birth, the nicotine and saccharin concentrations were reduced by $50 \%$ every 2 days until the mice were consuming only pure water. Nicotine and its metabolite cotinine take time to clear and will be present in mothers milk, thus it is likely that the pups continue to experience the presence of nicotine for sometime after the mothers were withdrawn. Saccharin/water consuming mothers were weaned off of the sweetened water in a similar step down fashion. Pups were weaned at 23 days and maintained in same sex litter-mate housed cages with free access to water and chow until age $60-90$ days.

\section{Nicotine/Cotinine Sample Preparation}

Nicotine levels in plasma were analyzed. Plasma samples were taken from a separate group of pregnant dams near the end of their pregnancy who were drinking at a rate similar to the dams providing the experimental offspring. Samples were treated with $500 \mu \mathrm{l}$ sodium tetraborate $(20 \mathrm{~g} / \mathrm{l}), 1.5 \mathrm{ml}$ of $50: 50$ dichloromethane: dichloroethane (Sigma-Aldrich), and $100 \mathrm{ng}$ each of deuterated nicotine and cotinine (Cerilliant, Austin, TX). The samples were centrifuged (4000 r.p.m. for $3 \mathrm{~min}$ ) and the organic phase was removed, washed by centrifugation with an additional volume of 50:50 dichloromethane: dichloroethane. The extract was then evaporated under nitrogen and reconstituted in $1 \mathrm{ml}$ of analytical grade methanol (Fisher Scientific).

\section{Nicotine/Cotinine Analysis}

Analysis was conducted by high-pressure liquid chromatography (Schimadzu SCL10A) coupled to a triple quadrupole mass spectrometer (MS) (Applied Biosystems, Model API 365). Injections $(50 \mu \mathrm{l})$ were made onto a $\mathrm{C}-18$ column (Restek Pinnacle ODS, $5 \mu \mathrm{m}$ pore size, $50 \times 4.6 \mathrm{~mm}$ ) and eluted at $0.2 \mathrm{ml} / \mathrm{min}$ with $90: 10$ acetonitrile/water (solvent 1) and $100 \%$ methanol/10 $\mathrm{mM}$ ammonium acetate $(\mathrm{pH}=6.7)$ (solvent 2) using the following program: $0-1.5 \mathrm{~min}$ at $90: 10$ solvent 1 : solvent $2 ; 1.5-5.1 \mathrm{~min}$ at $70: 30$ solvent 1 : solvent 2; 5.1-8 min at $90: 10$ solvent $1:$ solvent 2 . MS analysis was conducted in the positive ionization mode using a turbo ion-spray ionization source. MS parameters were $3800 \mathrm{~V}$ for the ion source voltage, $30 \mathrm{~V}$ for the orifice voltage, and $130 \mathrm{~V}$ for the ring voltage. Parent/daughter ions for nicotine/deuterated nicotine were selectively monitored at $163 / 106$ and 167/134, while cotinine/deuterated cotinine were monitored at $177 / 80$ and $180 / 80$, respectively. Analyte concentrations were determined as the ratio of the compound area to the area counts of the spiked deuterated analog. Differences in response between deuterated compounds and target analytes were compensated by creating calibration curves that span the range of the sample concentrations.

\section{Locomotor Activity Measurement}

Apparatus. Locomotor activity was tested using an automated system (San Diego Instruments, San Diego, CA) following the method described by Hess et al, 1996.

Testing. PNE and control mice were placed in individual photocell activity cages $(29.2 \times 50.0 \mathrm{~cm})$ coupled to 12 infrared beam detectors arranged in a $4 \times 8$ grid located $2 \mathrm{~cm}$ high from the floor of the cage. Beam breaks were computer recorded at $10 \mathrm{~min}$ intervals throughout the test. The testing period was $180 \mathrm{~min}$ long. Changes in beam status were assessed 18 times per second. Mice were habituated in the sound attenuated room for $1 \mathrm{~h}$ prior to testing. Locomotion was defined as actual beam interruptions. Data for each of the 10 min intervals was obtained and the total from the 18 intervals comprised the accumulated locomotion score. 


\section{Conditioned Place Preference}

Apparatus. Conditioned place preference boxes were constructed of plexiglas with two distinctly different $20 \times 20 \times 20 \mathrm{~cm}$ chambers connected by a $9 \times 10 \times 20 \mathrm{~cm}$ anteroom with a removable door. One chamber was covered with black and the other with white contact paper. The methods followed for the cocaine place preference task are described by Allan et al, 2001.

Conditioning. On day 1 , mice were placed in the anteroom of the conditioned place preference box and allowed access to both sides of the box for $10 \mathrm{~min}$. Basal activity was monitored and video taped. Basal activity was scored to test for a place bias before the start of the experiment and no significant pretest bias was observed in the mice. Assignment of cocaine-paired side was alternated, such that an equal number of mice were assigned the white side for cocaine as were assigned to the black side for cocaine. Placement in a box side was considered when both of the front feet were placed in a side. Training began on day 2 where each mouse received either an i.p. dose of cocaine $(4 \mathrm{mg} / \mathrm{kg}$, or saline) and confined to either the white or the black side of the box for $15 \mathrm{~min}$. Mice were returned to their home cage for $5 \mathrm{~h}$ and then given a second injection of either drug or saline which ever they did not receive in the first injection event, and were placed in the alternate chamber. Again the mouse remained confined in the alternate side of the box for a total of $15 \mathrm{~min}$. Pairing of chamber side (black or white) with injection condition (cocaine or saline) was counterbalanced across groups (PNE or control) and alternated for time of day (am or pm). This process of morning and afternoon injections followed with confinement for $15 \mathrm{~min}$ to the preassigned box side was repeated for 3 consecutive days (experimental days 2-4).

Testing. On day 5 , mice were placed in the anteroom and the door was removed. Mice were allowed access to either side of the box and the time spent in each chamber was recorded for $10 \mathrm{~min}$ total. A total of eight mice per group were tested for cocaine conditioned place preference. All conditioning and testing was carried out between 0900 and 1400 under dim illumination in a sound attenuated room with white noise present.

\section{Learned Helplessness}

Apparatus. A Coulbourn ${ }^{\mathrm{TM}}$ Habitest $^{\complement}$ shuttlebox with a stainless-steel grid floor for administration of the $0.3 \mathrm{~mA}$ footshock was used. The front and back were made of plexiglass. The sides, including a dividing guillotine door in the center, and the ceiling were aluminum. The apparatus was located within a sound-attenuated chamber. Ethanol (70\%) was used to clean the walls and floor after the removal of each mouse from the shuttlebox during training and testing. Method used for training and testing learned helplessness followed the procedure described by Caldarone et al, 2000.

Training. Groups consisted of six animals in each of six groups (two prenatal treatments $\times$ two genders $\times$ two training groups, shocked and no shock). Animals in the learned helplessness (LH-trained) group received 120 uncontrollable and unpredictable footshocks $(0.3 \mathrm{~mA}, 2 \mathrm{~s}$ duration) over the course of $1 \mathrm{~h}$. A probability for delivery of the footshock was assigned at 0.5 every $15 \mathrm{~s}$ and the animal was removed $30 \mathrm{~s}$ after the delivery of 120 shocks. The nonshocked (NS-trained) group was placed into the apparatus and given an hour exposure without any shock being delivered. Mice from each training group were removed at the end of the hour and allowed $24 \mathrm{~h}$ before being tested. Two mice were trained at a time, one LH-trained, and one NS-trained.

Testing. To test for LH, an escape deficit was measured during an active avoidance procedure. Animals were placed into the shuttlebox and given 30 trials with an intertrial interval of $30 \mathrm{~s}$. For the first five trials, a footshock and auditory cue ( $80 \mathrm{db}, 6 \mathrm{~Hz}$ clicker) came on at the start of the trial and, and after a 1-s delay the guillotine door raised. The last 25 trials initiated with the auditory cue and the door raising, the footshock was delayed for $3 \mathrm{~s}$. Latency for the mouse to escape through the door was measured as the time from the door raising to the time it closed. Sensors in each compartment of the shuttlebox turned off the footshock and tone and closed the guillotine door if the animal escaped through the raised door. If no escape was made $24 \mathrm{~s}$ after the start of the trial, the shock and tone terminated and the door closed.

\section{Trace Conditioning}

Apparatus. Animals were placed into a Coulbourn ${ }^{\mathrm{TM}}$ Habitest ${ }^{\odot}$ fear conditioning system equipped with a stainless-steel grid floor for administration of a foot shock. Method for training and testing trace fear conditioning was modified from the procedure described by Han et al, 2003.

Training. After $90 \mathrm{~s}$ of habituation, a $10 \mathrm{~s}$ tone of $80 \mathrm{~dB}$ was presented. After a $30 \mathrm{~s}$ delay a $1 \mathrm{~s}$ electric foot shock of $0.7 \mathrm{~mA}$ was presented. This cycle was presented a total of 10 times with a $210 \mathrm{~s}$ intertrial interval. Mice were then returned to their home cages.

Testing. At 24 hours following training mice were placed into placed in a clean standard housing cage with a small amount of clean standard bedding. After $4 \mathrm{~min}$ of acclimation, mice were exposed to the $10 \mathrm{~s}$ tone of $80 \mathrm{~dB}$, without subsequent shock, and then observed for freezing behavior for $170 \mathrm{~s}$ using a time sampling approach. Mice were observed for freezing behavior every $10 \mathrm{~s}$ throughout the $170 \mathrm{~s}$ testing period yielding a total of 17 observations. Movement, other than that associated with respiration, was recorded as a 1. Freezing behavior was recorded as a 0 . Animal behavior was analyzed in a blind fashion with regard to fetal nicotine exposure and drug treatment. All training was videotaped for subsequent viewing and documentation.

\section{RESULTS}

\section{Prenatal Nicotine Paradigm}

The average of nicotine consumption was $3.5 \pm 0.4 \mathrm{mg} / \mathrm{kg} /$ day. Average blood nicotine levels were $21 \pm 0.09 \mathrm{ng} / \mathrm{ml}$ of 
plasma. This level of consumption was comparable with other reports (Adriani et al, 2004; Lee et al, 2004; Li et al, 2005) but lower than those reported by Sparks and Pauly, 1999; Klein et al, 2004). The lower levels of drinking in the present study is likely do to the significantly lower levels of saccharin used to sweeten the nicotine solutions $(0.06 \%$ compared the commonly used $2.0 \%$ saccharin solutions). There were no significant differences in the number of pups per litter $(6.2 \pm 1.3$ for control litters and $6.5 \pm 1.8$ for PNE litters), neither in pup weight $(4.26 \pm 0.3$ for control litters and $5.08 \pm 0.4$ for PNE litters). Pups taken from eight pregnant dams for each treatment condition were used. No more than two pups from any given litter were used in each of the behavioral studies. Between six- to eight different litters were represented in any particular experimental group. On the occasion where two mice were taken from a given litter and assigned to the same experimental group, one male and one female were selected. In all of the analyses, the $n$ used is the number of mice and not the number of litters. However, in most cases the number of mice was equal to the number of litters used. Only in the cocaine place preference test, six different litters were used. All behavioral tests were performed blind to the mice prenatal status.

\section{Locomotion Testing}

A total of eight mice per group were tested. Both PNE mice displayed higher spontaneous locomotor activity (Figure 1). A two prenatal treatment $x$ two gender analysis of variance (ANOVA) revealed a significant effect of prenatal treatment, $\mathrm{F}(1,28)=4.6, p<0.04$. There was no main effect of gender nor was an interaction between gender and prenatal condition detected.

\section{Conditioned Place Preference}

As shown in Figure 2, an increased preference for the cocaine-paired side of the apparatus was observed in PNE mice. A two prenatal treatment $\times$ two gender ANOVA revealed a significant effect of prenatal treatment, $\mathrm{F}(1,28)=4.11, p<0.05$. There was no main effect of gender nor was an interaction between gender and prenatal condition detected.

\section{Trace Conditioning}

Fear associated freezing to the tone was assessed using a separate group $(n=8)$ of prenatal exposed offspring (Figure 3), ANOVA showed a prenatal main effect of $\mathrm{F}(1,28)=6.11, \quad p<0.02$. A main effect of gender $\mathrm{F}(1,28)=5.7, p<0.02$, and a significant interaction of gender $\times$ prenatal treatment $\mathrm{F}(1,28)=12.12, p<0.001$ were also observed. The likely source of the interaction is the improved performance of the male PNE while female PNE do not display a significant improved learning score, as determined by Bonferroni post hoc $(t=2.58, p<0.05)$. It should be noted that there was no significant freezing in any of the treatment or gender groups during the $4 \mathrm{~min}$ period prior to tone onset, suggesting that there are no baseline freezing differences.

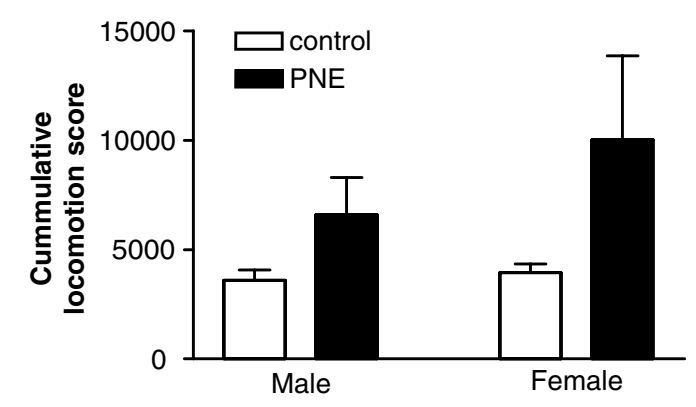

Figure I Prenatal nicotine exposure increased locomotion in both male and female offspring. The effect of prenatal treatment on spontaneous locomotion in male and female adult offspring is presented as mean $( \pm$ SEM) cumulative locomotion in a 180 min continuous test period, $n=8$ mice per group.

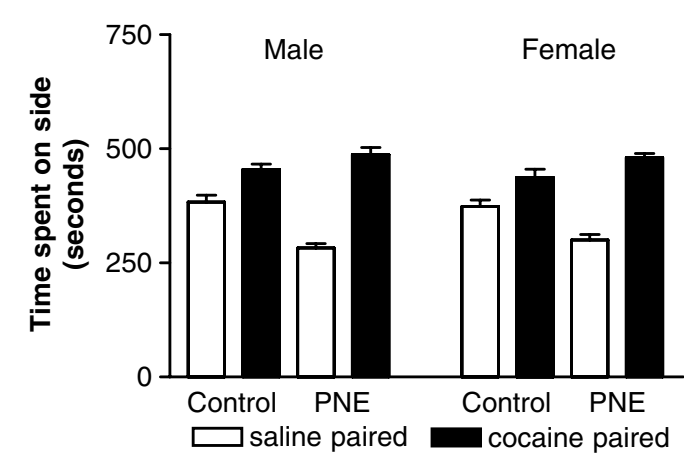

Figure 2 Prenatal nicotine exposure increased the preference for cocaine place preference. Cocaine place preference in saccharin (Con) or nicotine (PNE) prenatally exposed in male and female adult offspring. Data is presented as time spent on cocaine or saline-paired side of the box. Time spent in cocaine side is in the solid bars and time spent in the saline-paired side is in the open bars. Time spent in the antechamber is not presented. Eight male and eight female mice were tested.

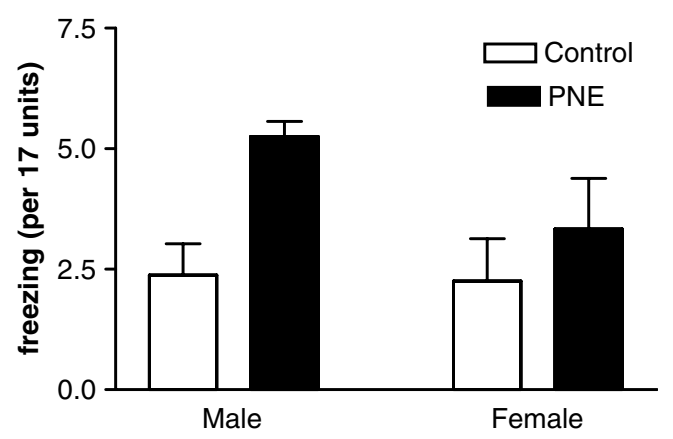

Figure 3 Prenatal nicotine exposure increased learning in a trace fear conditioning task. Trace fear conditioned freezing to the tone stimulus in saccarhin (open bars) and nicotine (closed bars) prenatally exposed. Freezing scores are presented in units of 10 s observation blocks for a total of 17 blocks or $170 \mathrm{~s}$. A score of I for each block indicates complete freezing behavior while a score of zero indicates no learning. Perfect learning would yield a score of six. The data are mean $( \pm$ SEM) from $n=8$ mice per group.

\section{Learned Helplessness}

Learned helpless behavior was assessed in a naïve group of PNE and control male and female mice $(n=6$, Figure 4$)$. A two-way multivariate ANOVA revealed a significant effect of 


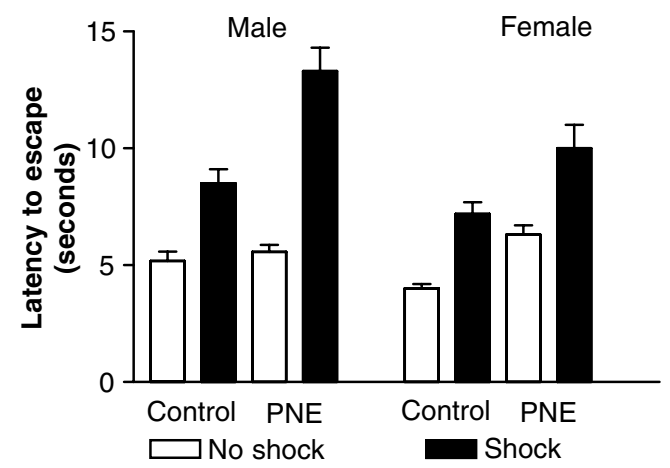

Figure 4 Prenatal nicotine increased the latency to escape following learned helplessness training. The effect of prenatal nicotine (PNE) or saccharin (Control) on escape latency in the no-shock (open bars) and shocked, learned helplessness (solid bars) conditions in male (left panel) and female (right panel) adult offspring. Data presented are mean ( \pm SEM) from six mice per condition.

prenatal treatment $\mathrm{F}(1,20=39.7, p<0.0001)$ and a significant effect of gender, $\mathrm{F}(1,20)=6.4, p<0.05$. There was an interaction of gender by prenatal treatment, $\mathrm{F}(1,20)=4.8$, $p<0.05$, as well as main effect for the shock condition (LH vs no-shock group), $\mathrm{F}(1,20)=64.2, p<0.0001$ ) and a significant interaction between prenatal condition and shock condition, $F(1,20)=17.78, p<0.0004$. The source of this interaction is that neither gender nor prenatal condition had an effect on escape latency in the no-shock condition, while in the male offspring of PNE who had LH training there was a significant increase in the latency to escape following learned helplessness training as determined by Bonferroni post hoc $(t=13.3, p<0.001)$.

\section{DISCUSSION}

Similar to rat-models of PNE, increased spontaneous locomotion was observed in adult mice exposed to nicotine during intrauterine and early neonatal stages of neural development. In this study, however, pregnant dams had free access to nicotine/saccharin or pure water solutions. This finding indicates that the hyperactive behavior that has been observed in rats that were exposed to nicotine prenatally using forced-administration paradigms is not likely the result of an interaction between the stress reaction potentially caused by forced nicotine administration to pregnant mothers and prenatal nicotine exposure. Thus, together with clinical and epidemiological studies showing an increased prevalence of ADHD in children born from mothers voluntarily consuming nicotine, our findings indicate that intrauterine brain exposure to nicotine by itself is a risk factor for the emergence of hyperlocomotive behaviors in exposed subjects. Regarding the possibility that these behavioral abnormalities could be mediated by impaired brain nutrition (Slotkin, 1998), no significant differences were observed in the number and weight of pups born from nicotine exposed dams and control dams. Even though we cannot rule out subtle effects of nicotine on placental or brain vascular integrity, which may indirectly impair brain development, it seems more likely that the abnormal behavior observed in PNE mice was caused by the pathological activation of acetylcholine nicotinic receptors
(AchNR) during early stages of brain development (Slotkin, 1998; Slotkin, 2004). Consistent with this interpretation, a recent study suggests that the normal activation of AchNR located in cortico-thalamic terminals plays a critical role in the development of neural circuits involved in the regulation of normal fear-associated learning (King et al, 2003). In this study, knocking-out the $\beta 2$ subunit of these receptors in neonatal, but not adult, mice resulted in increased learning of a fear-associated learning task known as passive avoidance. Paralleling these findings, we found that PNE mice exhibited increased learning of fear-associated cues. Since blunted presynaptic cholinergic activity has been described in PNE rats (Navarro et al, 1989; Zahalka et al, 1992), the surprising improvement in the learning of fearconditioned cues observed in PNE mice might be the result of blunted presynaptic cholinergic activity during early stages of brain development. Consistent with this interpretation, increased learning of passive avoidance was also reported in PNE rats in another study (Genedani et al, 1983). These findings raise the intriguing possibility that the risk of developing neuropsychiatric syndromes associated with augmented learning of fear associated cues such as post-traumatic stress disorder (PTSD) might be increased in individuals who were exposed to nicotine prenatally. Consistent with this hypothesis, a recent study found an increased prevalence of ADHD in patients with PTSD (Adler et al, 2004). Thus, it is possible that some subtypes of PTSD, coexisting or being preceded by ADHD, may share common neurodevelopmental origins with this condition, one of them being, perhaps, PNE. Future clinical and epidemiological studies may explore this hypothesis.

In the current study, PNE mice also displayed an increased latency to escape in the learned helplessness paradigm. To the best of our knowledge this is the first study to show a behavioral pattern suggesting a vulnerability to develop depressive-like responses in PNE animals. Together with epidemiological studies reporting an increased prevalence of MDD in PNE children and adolescents (Fergusson et al, 1998; Wu and Anthony, 1999) our study suggest that abnormal activation of AchNR during prenatal and early neonatal stages of brain development may affect the maturation of brain circuits critical for mood regulation during adulthood. Consistent with this hypothesis, PNE rats have been shown to have decreased cortical binding of [H3] paroxetine, a well known marker of the functional integrity of the serotonergic system (Xu et al, 2001). Likewise, increased 5HT-2 and 5HT-1A receptor binding were also recently reported in the cerebral cortex of these animals (Slotkin et al, 2005). A recent epidemiologicgenetic study strongly suggests that the functional state of the serotonergic system may play a critical role as modulator of the risk of developing depressive episodes during life-stress situations in vulnerable subjects (Caspi et al, 2003). Likewise, a growing body of experimental evidence indicates that the functional state of the serotonergic system during early stages of neural development plays an enduring role in shaping the way that animals may face stress situations later in life (Gross et al, 2002; Ansorge et al, 2004; Sibille and Lewis, 2006). Thus, the abnormalities reported in the serotonergic system in PNE rats, and the increased latency to escape following an inescapable stress experience observed in PNE mice, suggest that a causal link 
could be mediating the association observed between PNE and MDD in epidemiological studies. Future studies exploring the mechanisms involved in this interesting phenomenon are warranted.

An increased preference for a place previously associated with cocaine was also observed in PNE mice. Since clinical and epidemiological studies have reported high rates of substance abuse problems in PNE children and adolescents (Fergusson et al, 1998), our results suggest that a direct causal link may also underlie this association.

Overall the variety of behavioral abnormalities observed in adult mice whose brains were exposed to nicotine during prenatal and early neonatal stages of neural development stresses the clinical relevance of developing aggressive strategies to identify and treat pregnant women addicted or abusing tobacco (Slotkin, 1998, 2004). From the clinical neuroscience point of view, uncovering the molecular and cellular mechanisms, as well as the precise brain circuits involved in the generation of these neurodevelopmentally induced abnormalities in PNE mice may shed some light about the causes of disabling neuropsychiatric conditions.

\section{ACKNOWLEDGEMENTS}

We thank Julie Chynoweth for her technical assistance in generating the nicotine exposed offspring for these studies. We also thank Dr John (Jake) McDonald at The Lovelace Respiratory Research Institute in Albuquerque, New Mexico and The New Mexico Center for Environmental Health Sciences (ES P30-012072-05) for analysis of the nicotine plasma levels. This work was supported by Tobacco Settlement Funds through University of New Mexico Research Allocation Committee provided to AMA.

\section{REFERENCES}

Adler LA, Kunz M, Chua HC, Rotrosen J, Resnick SG (2004). Attention-deficit/hyperactivity disorder in adult patients with posttraumatic stress disorder (PTSD): Is ADHD a vulnerability factor? J Atten Disord 8: 11-16.

Adriani W, Granstrem O, Macri S, Izykenova G, Dambinova S, Laviola G (2004). Behavioral and neurochemical vulnerability during adolescence in mice: studies with nicotine. Neuropsychopharmacology 29: 869-878.

Allan AM, Engel SR, Savage DD, Galindo R, Cynoweth J (2001). Conditioned place preference for cocaine is attenuated in mice over-expressing the 5-HT3 receptor. Psychopharmacology 158: $18-27$.

Ansorge MS, Zhou M, Lira A, Hen R, Gingrich JA (2004). Early-life blockade of the 5-HT transporter alters emotional behavior in adult mice. Science 306: 879-881.

Caldarone BJ, George TP, Zachariou V, Picciotto MR (2000). Gender differences in learned helplessness behavior are influenced by genetic background. Pharmacol Biochem Behav 66: 811-817.

Caspi A, Sugden K, Moffitt TE, Taylor A, Craig IW, Harrington H et al (2003). Influence of life stress on depression: moderation by a polymorphism in the 5-HTT gene. Science 301: 386-389.

Cornelius MD, Ryan CM, Day NL, Goldschmidt L, Willford JA (2001). Prenatal tobacco effects on neuropsychological outcomes among preadolescents. J Dev Behav Pediatr 22: 217-225.

Ernst M, Moolchan ET, Robinson ML (2001). Behavioral and neural consequences of prenatal exposure to nicotine. J Am Acad Child Adolesc Psychiatry 40: 630-641.
Eskenazi B, Prehn AW, Christianson RE (1995). Passive and active maternal smoking as measured by serum cotinine: the effect on birthweight. Am J Public Health 85: 395-398.

Fendt M, Fanselow MS, Koch M (2005). Lesions of the dorsal hippocampus block trace fear conditioned potentiation of startle. Behav Neurosci 119: 834-838.

Fergusson DM, Woodward LJ, Horwood LJ (1998). Maternal smoking during pregnancy and psychiatric adjustments in late adolescence. Arch Gen Psychiatry 55: 721-727.

Fried PA, Watkinson B, Gray R (2003). Differential effects on cognitive functioning in 13- to 16-year-olds prenatally exposed to cigarettes and marihuana. Neurotoxicol Teratol 25: 427-436.

Genedani S, Bernardi M, Bertolini A (1983). Sex-linked differences in avoidance learning in the offspring of rats treated with nicotine during pregnancy. Psychopharmacology (Berlin) 80: 93-95.

Gross C, Zhuang X, Stark K, Ramboz S, Oosting R, Kirby L et al (2002). Serotonin1A receptor acts during development to establish normal anxiety-like behaviour in the adult. Nature 416: 396-400.

Han CJ, O’Tuathaigh CM, van Trigt L, Quinn JJ, Fanselow MS, Mongeau $\mathrm{R}$ et al (2003). Trace but not delay fear conditioning requires attention and the anterior cingulate cortex. Proc Natl Acad Sci USA 100: 13087-13092.

Hess EJ, Collins KA, Wilson MC (1996). Mouse model of hyperkinesis implicates SNAP-25 in behavioral regulation. J Neurosci 16: 3104-3111.

King SL, Marks MJ, Grady SR, Caldarone BJ, Koren AO, Mukhin AG et al (2003). Conditional Expression in Corticothalamic Efferents Reveals a Developmental Role for Nicotinic Acetylcholine Receptors in Modulation of Passive Avoidance Behavior. J Neurosci 23: 3837-3843.

Klein LC, Stine MM, Vandenbergh DJ, Whetzel CA, Kamens HM (2004). Sex differences in voluntary nicotine consumption by adolescent mice: a dose-response experiment. Pharmacol Biochem Behav 78: 13-25.

Kofman O (2002). The role of prenatal stress in the etiology of developmental behavioural disorders. Neurosci Biobehav Rev 26: 457-470.

Lee M, Chen K, Shih JC, Hiroi N (2004). MAO-B knockout mice exhibit deficient habituation of locomotor activity but normal nicotine intake. Genes Brain Behav 3: 216-227.

Li XC, Karadsheh MS, Jenkins PM, Stitzel JA (2005). Genetic correlation between the free-choice oral consumption of nicotine and alcohol in C57BL/6JxC3H/HeJ F2 intercross mice. Behav Brain Res 157: 79-90.

Linnet KM, Wisborg K, Obel C, Secher NJ, Thomsen PH, Agerbo E et al (2005). Smoking during pregnancy and the risk for hyperkinetic disorder in offspring. Pediatrics 116: 462-467.

Martin JA, Kochanek KD, Strobino DM, Guyer B, MacDorman MF (2005). Annual summary of vital statistics. Pediatrics 115: 619-634.

Maughan B, Taylor A, Caspi A, Moffitt TE (2004). Prenatal smoking and early childhood conduct problems: testing genetic and environmental explanations of the association. Arch Gen Psychiatry 61: 836-843.

Mick E, Biederman J, Faraone SV, Sayer J, Kleinman S (2002). Case-control study of attention-deficit hyperactivity disorder and maternal smoking, alcohol use, and drug use during pregnancy. J Am Acad Child Adolesc Psychiatry 41: 378-385.

Milberger S, Biederman J, Faraone SV, Chen L, Jones J (1996). Is maternal smoking during pregnancy a risk factor for attention deficit hyperactivity disorder in children? Am J Psychiatry 153: 1138-1142.

Navarro HA, Seidler FJ, Eylers JP, Baker FE, Dobbins SS, Lappi SE et al (1989). Effects of prenatal nicotine exposure on development of central and peripheral cholinergic neurotransmitter 
systems. Evidence for cholinergic trophic influences in developing brain. J Pharmacol Exp Ther 251: 894-900.

Olsen J (1992). Cigarette smoking in pregnancy and fetal growth Does the type of tobacco play a role? Int J Epidemiol 21: 279-284.

Sibille E, Lewis DA (2006). SERT-ainly involved in depression, but when? Am J Psychiatry 163: 8-11.

Slawecki CJ, Samson HH, Hodge CW (1997). Differential changes in sucrose/ethanol and sucrose maintained responding by independently altering ethanol or sucrose concentration. Alcohol-Clin Exp Res 21: 250-260.

Slotkin TA (1998). Fetal nicotine or cocaine exposure: which one is worse? J Pharmacol Exp Ther 285: 931-945.

Slotkin TA (2004). Cholinergic systems in brain development and disruption by neurotoxicants: nicotine, environmental tobacco smoke, organophosphates. Toxicol Appl Pharmacol 198: $132-151$.

Slotkin TA, Tate CA, Cousins MM, Seidler FJ (2005). Prenatal nicotine exposure alters the responses to subsequent nicotine administration and withdrawal in adolescence: serotonin receptors and cell signaling. Neuropsychopharmacology, 7 December [Epub ahead of print].
Sparks JA, Pauly JR (1999). Effects of continuous oral nicotine administration on brain nicotinic receptors nad responsiveness to nicotine in C57Bl/6 mice. Psychopharmacolgy 141: 145-153.

Thapar A, Fowler T, Rice F, Scourfield J, van den Bree M, Thomas $\mathrm{H}$ et al (2003). Maternal smoking during pregnancy and attention deficit hyperactivity disorder symptoms in offspring. Am J Psychiatry 160: 1985-1989.

Weissman MM, Warner V, Wickramaratne PJ, Kandel DB (1999). Maternal smoking during pregnancy and psychopathology in offspring followed to adulthood. J Am Acad Child Adolesc Psychiatry 38: 892-899.

Wu LT, Anthony JC (1999). Tobacco smoking and depressed mood in late childhood and early adolescence. Am J Pub Health 89: 1837-1840.

Xu Z, Seidler FJ, Ali SF, Slikker Jr W, Slotkin TA (2001). Fetal and adolescent nicotine administration: effects on CNS serotonergic systems. Brain Res 914: 166-178.

Zahalka EA, Seidler FJ, Lappi SE, McCook EC, Yanai J, Slotkin TA (1992). Deficits in development of central cholinergic pathways caused by fetal nicotine exposure: differential effects on choline acetyltransferase activity and [3H] hemicholinium-3 binding. Neurotoxicol Teratol 14: 375-382. 